\title{
El plagio en el contexto del derecho
} de autor* / Plagiarism

in the context of the author's copyright

\footnotetext{
* Recibido: 13 de diciembre de 2016. Aceptado: 9 de febrero de 2017.
}

Tla-Melaua, revista de Ciencias Sociales. Facultad de Derecho y Ciencias Sociales. Benemérita Universidad Autónoma de Puebla, México / Isss: 1870-6916 / Nueva Época, año 11, núm. 42, abril-septiembre 2017, pp. 48-66. 
Sandra Timal López*

Francisco Sánchez Espinoza**

"Ser un plagiario equivale a ser un falso autor, a no tener voz, ni estilo literario; a ser nada ni nadie..."

Perromat, Agustín.

RESUMEN

La práctica del plagio en el ámbito de la investigación es frecuente. Se trata de una acción desleal que vulnera el derecho de autor. Sin embargo, el marco en que se desenvuelve esta práctica carece de sanción frente a la violación del derecho moral que le es intrínseco al autor de una obra. Proteger el derecho moral y no únicamente el patrimonial de quien es creador de una obra, específicamente en las tesis, es el tema de la presente investigación.

\section{PALABRAS CLAVE}

Autor, derecho de autor, derecho moral, derecho patrimonial, originalidad, plagio.

\section{A B S T R A C T}

Plagiarism in the field of research is frequent. It is an unfair action that infringes on the author's property rights (copyright). However, the framework in which this practice unfolds lacks sanctions against the violation of the moral right that is infringed to the work of any author. Protecting the moral right and not only the patrimonial of the creator of a work, specifically in a thesis, is the objective of the present investigation.

\section{KEYWORDS}

Author, copyright, moral right, patrimonial right, originality, plagiarism.

\footnotetext{
* Estudiante del programa de doctorado en Derecho de la Benemérita Universidad Autónoma de Puebla, México. (timalsandy@hotmail.com)

** Profesor investigador en la Facultad de Derecho y Ciencias Sociales de la Benemérita Universidad Autónoma de Puebla. (frasaes_7@hotmail.com)
} 

plagio académico / 4. Otras prácticas de deshonestidad académica / 5. El delito de plagio previsto en la legislación federal / 6. Un estudio de derecho comparado / 7. Herramientas online para detectarlo / 8. Prácticas de deshonestidad académica / 9. ¿Cómo frenar su uso en las tesis? / 10. Conclusiones

\section{INTRODUCCIÓN}

En el contexto del estudio del derecho, la palabra plagio puede estudiarse en dos ramas: el derecho penal y el derecho intelectual, específicamente en el derecho de autor. En este último debemos ubicarnos para entender el desarrollo de la presente investigación. En el derecho romano se llamaba "plagio" al acto de robar niños, esclavos y ganado; años después, se empezó a usar en el derecho penal como sinónimo de secuestro. Sin embargo, también se emplea en el derecho de autor. Hay varios conceptos que aluden a que comete plagio aquella persona que roba la idea de un autor para plasmarla en una obra que hace pasar como propia.

Resulta interesante entender cómo es que la palabra plagio empezó a utilizarse (en el derecho romano) para calificar la acción de robar personas y cosas. En el siglo i d. C. se empieza a usar para referirse al robo de ideas; de hecho, se le atribuye al poeta Marcial ${ }^{1}$ el uso del término "plagiario" para hacer alusión, en la literatura, a la persona que le ha robado sus obras. El poeta Marcial escribió la siguiente frase en la que usó por vez primera dicha palabra:

"Te encomiendo, Quinciano, mis libritos. Si es que puedo llamar míos los que recita un poeta amigo tuyo. Si ellos se quejan de su dolorosa esclavitud, acude en su ayuda por entero. Y cuando aquél se proclame su dueño, di que son míos y que han sido liberados. Si lo dices bien alto tres o cuatro veces, harás que se avergüence el plagiario".²

Desde el siglo I d. C. (con Marcial) comienza el estudio del plagio en el contexto del derecho de autor, pues hace referencia al robo de ideas y no al robo de cosas tangibles. En el siglo XIX se decía que el plagio es "La máscara bajo la cual oculta su deformidad un ser repugnante y rastrero para poder figurar

\footnotetext{
${ }^{1}$ Gutiérrez, Angélica, "El plagio literario", Derecho y cambio social, 21 de marzo, 2009. [Consulta: 12 de agosto, 2016]. Disponible en: https://dialnet.unirioja.es/descarga/articulo/5500739.pdf

2 González, Mario, "Teoría de la arquitectura", Cátedra González, 8 de marzo, 2011. [Consulta: 12 de agosto, 2016]. Disponible en: https://dialnet.unirioja.es/descarga/articulo/5500739.pdf
} 
entre las gentes sin que estas hagan ascos a su fealdad y a sus miserias, o que el plagio constituye una falta literaria que entraña mayor inmoralidad, la más repugnante y la que debe considerarse como patente de incapacidad y símbolo de vergüenzas". 3

En la actualidad el plagio, en el contexto del derecho de autor, es un tema muy común, pero al mismo tiempo poco explorado. Hablar de plagio implica ubicarnos en el ámbito del arte y la literatura, pues son obras artísticas y literarias las que pueden ser sujetas de plagio, es decir, pueden ser copiadas, imitadas y robadas con el propósito de hacerlas pasar como propias. Sin embargo, las obras literarias son las que con mayor frecuencia se plagian. Esta práctica desleal se desenvuelve entre quienes están en constante contacto con dichas obras. Entonces llegamos a la parte medular de esta investigación, pues nos ubicamos en el contexto de los investigadores, de los profesores y de los alumnos, dado que son estos tres grupos de personas quienes cometen plagio. La acción de plagiar no es nueva, pero actualmente se ha vuelto una práctica desmedida debido a que la herramienta más usada para realizar investigación es internet. La emplean, con frecuencia, un mayor número de personas, de todas edades y profesiones.

Anteriormente, para realizar una investigación se acudía a las bibliotecas, se transcribían textos a mano, se visitaban las hemerotecas; hoy, el uso de internet facilita la búsqueda de todo tipo de información, pero al mismo tiempo se convierte en el medio más común para copiar y pegar textos de notas periodísticas y hasta tesis. Hacer investigación usando internet no significa "plagiar", pues este término implica que quien toma la idea o el texto de una obra o de un autor no le da el crédito al mismo, violando así el derecho moral al que es acreedor el autor de la obra. Por lo tanto, se comete plagio cuando el autor de una obra no otorga el reconocimiento al autor o autores de quienes obtuvo la información para su investigación.

Se debe ser partidario de fomentar una cultura por el respeto del derecho moral de autor, atendiendo a que este derecho no requiere de ningún trámite para ser otorgado al autor de una obra, sino que, por el simple hecho de haberla creado, le pertenece.

\section{Antecedentes DEL PLAgio}

Para adentrarnos en el tema del plagio, comenzaremos por una anécdota que refleja de manera sencilla los primeros ejemplos de la existencia del plagio.

"En el siglo II a. C. se organizó en Egipto una competencia literaria donde los poetas recitaban sus creaciones frente al público y a un

${ }^{3}$ Wampersin, Mario, El plagio en la literatura, España, Cádiz, 1893, p. 6. 
distinguido comité calificador. Uno de los jueces era Aristófanes el gramático, conocido también como Bizancio. El faraón en aquella época Ptolomeo Filadelfo, escuchó con atención a los concursantes y al final preguntó a los jueces por el veredicto. Aristófanes señaló que se debía premiar al poeta que peores versos había declamado. Tras ser consultado por la razón de tan peculiar parecer, el sabio afirmó que el peor poeta del certamen era el único que no había recitado versos de otros líricos, que era el único que había escrito y referido sus propias composiciones. El faraón y su séquito dudaban, así que para despejar cualquier incógnita, se dirigieron a la biblioteca de Alejandría (la más grande del mundo Antiguo, con 900000 manuscritos) en donde Aristófanes desenmascaró uno a uno a los participantes del certamen comparando sus creaciones con fragmentos de otros autores. El faraón, hijo de Ptolomeo I Sóter, el mismísimo fundador de la biblioteca, ordenó que los presuntos poetas fueran encerrados por robo. Al mismo tiempo, premió a Aristófanes nombrándolo director de la biblioteca". ${ }^{4}$

En la época greco-romana, se hablaba de la imitación de obras y de la emulación de modelos clásicos. Se entendía por "imitar" el acto de copiar, pues el aprendiz sólo podía adquirir conocimiento copiando las ideas, ejemplos y enseñanzas de sus maestros. Un aprendiz, al plasmar en un texto la idea de su maestro, estaba generando y transmitiendo conocimiento, de modo que el hecho de "imitar" a su profesor no podía ser una mala práctica. Por "emular" se entendía también el acto de imitar; pero se usaba en las obras teatrales y representaciones artísticas, no en textos. De modo que en esa época imitar y emular a los autores originales eran buenas prácticas.

\section{EL PLAGIO ACADÉmiCO}

El plagio en el contexto de la literatura es bastante antiguo, y ha trascendido hasta la actualidad. A partir de este apartado nos enfocaremos en el desarrollo del plagio en un contexto actual.

El Glosario de la Organización Mundial de la Propiedad Intelectual define el plagio como: "El acto de ofrecer o presentar como propia, en su totalidad o en parte, la obra de otra persona, en una forma o contexto más o menos alterados". ${ }^{5}$

\footnotetext{
${ }^{4}$ Ramírez, Soledad, "Un ladrón de literatura: el plagio a partir de la transtextualidad", Literatura y letras, 13 de enero, 2010. [Consulta: 10 de agosto, 2015]. Disponible en: https://sites.google.com/site/.../lasprimeras-civilizaciones-mesopotamia-y-egipto

${ }^{5}$ Rojas, Miguel Ángel, "Plagio académico", Revista Colombiana de Anestesiología, vol. 38, núm. 4. [Consulta: 16 de julio, 2016]. Disponible en: http://www.scielo.org.co/scielo.php?script=sci_arttext\&pid $=\mathrm{S} 0120-33472010000400010$
} 
Delia Lipszyc señala que "El plagio es el apoderamiento ideal de todos o de algunos elementos originales contenidos en la obra de otro autor presentándolos como propios". ${ }^{6}$ Para continuar con el estudio de la acción de plagiar, citaremos a Rosselot, quien dice:

"Se entiende como plagio la apropiación, presentación y utilización de material intelectual ajeno, sin el debido reconocimiento de su fuente original. Constituye, por lo tanto, un acto fraudulento, en el cual existe presunción de intencionalidad, en el sentido de hacer parecer un determinado conocimiento, labor o trabajo, como producto propio; y de desconocer la participación de otros en su generación, aplicación o en su perfeccionamiento". ${ }^{7}$

Después de la definición y los conceptos escritos, podemos confirmar lo que se decía en la introducción, que el plagio en el contexto del derecho de autor nos remite a la vida académica, donde los principales actores son investigadores, profesores y alumnos. Es sabido que, en la vida de todo estudiante, sin importar el grado, existen un sinnúmero de obras a su alcance, mismas que se usan para desarrollar desde una opinión, un resumen, un ensayo, una paráfrasis e incluso tomar una postura metodológica ante un tema específico. Para ello, necesita forzosamente partir de algo existente, ya sea plasmado en una obra impresa, en un audio o en cualquier medio posible a su alcance. Parece bien que el estudiante acuda a una obra, la lea, la estudie, la asimile, la interprete y escriba al respecto. Pero entonces, ¿qué error comete el estudiante, para que su trabajo pueda calificarse de plagio? La respuesta atiende a que la mayoría de las veces el estudiante comete el error de omitir dar el crédito al autor que escribió la obra de donde retoma sus ideas.

Escuchamos muy a menudo decir que el plagio es el robo de una idea, es el "copiar y pegar" de la actualidad. En ese tenor, estrictamente se entiende que al calificar al plagio de una acción que implica "el robo de una idea" hay un elemento que subyace en dicha acción, es decir, esa acción de robar implica el apoderamiento sin consentimiento y sin derecho de una idea. ¿Qué acaso no es lo que todos hacemos? Todos en algún momento hemos leído la idea de otro y hasta llegamos a decir: como dice el autor " $\mathrm{x}$ ", citando al autor "z", como lo dijo en su obra "y". Lo anterior implica ocupar, usar, apoderarse de la idea de otro; y eso no lo juzgamos como plagio, al contrario,

\footnotetext{
${ }^{6}$ Lipszyc, Delia, Violaciones a los derechos de autor y los derechos conexos. Sanciones civiles y penales. Seminario Regional de la OMPI sobre derecho de autor y derechos conexos para jueces de Centroamérica y Panamá, Costa Rica, 1994, p. 19. ${ }^{7}$ Rosselot, Eduardo, et al., "Plagio intelectual. Documento de la comisión de ética de la facultad de medicina de la universidad de Chile", Revista médica de Chile, 2008, p. 136.
} 
lo justificamos diciendo que citamos, que hacemos referencia al autor, incluso le damos sus créditos.

En la obra "Por favor ¡Plágienme!”, el discurso de Laiseca ${ }^{8}$ nos explica que el plagio se funde, pareciera que se esconde, entre otros verbos, como citar, repetir y reeditar. Desde esta perspectiva, el hecho de citar, repetir o reeditar la obra o la idea de un autor, implica un plagio, mismo que no se castiga porque se considera una tradición. Es algo normal y aceptado por la sociedad, incluso hasta se ve provechoso este método de citas para fines didácticos. El plagio se convierte en un problema en la medida en que se usan las citas. Se ha llegado a establecer legislaciones que regulan el número de palabras, notas musicales o versos que pueden ser citados sin que se vulnere el derecho de autor.

$\mathrm{El}$ derecho de autor indica que debe sancionarse a quien haga pasar como propia una obra (de la índole que sea). El plagio en las aulas siempre ha estado presente. Quienes se ven inmersos en el ámbito de la investigación plagian, copian; pero esas acciones no pueden ser castigadas sino hasta el momento en que se registran a nombre de otro.

En derecho de autor es importante destacar conceptos como "originalidad", misma que es una condición necesaria para la protección.

"La originalidad o individualidad se concreta en que la obra exprese lo propio de su autor, que lleve la impronta de su personalidad, lo que no debe confundirse con novedad, pues en derecho de autor, a diferencia de lo que ocurre con las invenciones en el campo de la propiedad industrial, no se requiere que la obra sea novedosa". ${ }^{9}$

"El autor, por el solo hecho de la creación, goza de una tutela que se le reconoce sobre su obra desde dos perspectivas: por un lado, la protección de su esfera personal en relación con su producción intelectual y, por otro, la facultad de autorizar o prohibir la explotación de su creación". ${ }^{10}$

Resulta pertinente recalcar que el autor de una obra goza de derechos patrimoniales y morales sobre la obra que ha creado. Los primeros se traducen en una afectación a su patrimonio y por tanto son traducibles en dinero; además, cuando estos derechos se ven vulnerados, el autor puede realizar el procedimiento civil correspondiente para que sea resarcido el daño. Es el derecho moral que tiene el autor el que más violaciones sufre, pues cada vez que una persona no da el crédito al autor está vulnerando el derecho

\footnotetext{
${ }^{8}$ Laiseca, Alberto, Por favor, iplágienme!, Argentina, Eudeba, 2013, p. 19.

${ }^{9}$ Lypszyc, Delia, Derecho de autor y derechos conexos, Chile, UnEsco, 1993, p. 65.

${ }^{10}$ Antequera Parrilli, Ricardo, El nuevo derecho de autor en el Perú, Perú, Perú Reporting, 1996, p. 69.
} 
que le corresponde. Lo que resulta preocupante en este sentido es que esta "vulneración al derecho moral del autor" es la más común en el campo de la investigación.

Es importante hacer hincapié en que si bien es cierto que existen procedimientos civiles a través de los cuales el autor que ha sido plagiado puede reclamar la afectación al derecho patrimonial que le corresponde. También es cierto que en el ámbito académico no existe sanción alguna a la violación del derecho moral que le corresponde al autor.

Una vez que hemos establecido la importancia de la originalidad en el derecho de autor y los derechos de los que goza, es importante encuadrar la expresión "plagio académico".

"El plagio académico ocurre cuando quien escribe usa repetidamente más de cuatro palabras de una fuente impresa sin el uso de comillas $\mathrm{y}$ sin una referencia precisa a la fuente original en un trabajo que el autor presenta como su propia investigación y estudio. El parafraseo continuo sin la intervención propia de otra persona es también una forma de plagio en los trabajos académicos". ${ }^{11}$

Derivado del párrafo anterior, podemos observar que es un concepto, no es una definición de plagio académico. Resulta exageradamente pequeño el número de palabras que establece (cuatro) para determinar que existe plagio. Si nos apegáramos a conceptos como ese, todos cometeríamos plagio.

En ese mismo tenor, podemos hacer alusión al parafraseo en los textos académicos, el cual es válido siempre que se respete el argumento del texto original; es decir, en el parafraseo no debe dominar la idea de quien escribe.

Bajo el entendido de que realiza plagio quien hace pasar como suya una idea, texto u obra que fue creada por otra persona, podemos situarnos en el escenario más común de esta práctica: las aulas. Desde el nivel básico hasta el nivel superior, es fácil percibir la práctica del plagio a través de dos formas comunes:

- Cuando se usan ideas textuales de otro y no se colocan entre comillas.

- Cuando no se da el crédito correspondiente al autor de lo que se está escribiendo.

Esta práctica del plagio es una de las actividades que actualmente los estudiantes justifican con argumentos como "la información está al alcance de todos, por tanto las ideas son de todo el mundo". Lo cierto es que ese argumento

\footnotetext{
${ }^{11}$ Hexham, Irving, "Parafrasear", Seminario de Educación Superior UNAM, 24 de mayo, 2013. [Consulta: 26 de abril, 2015]. Disponible en: www.ses.unam.mx/curso2014/pdf/plagioacademico.ppt
} 
no sirve para justificar que se lleve a cabo esta práctica; más bien parece justificar la inadecuada técnica para citar.

\section{OTRAS PRÁCTICAS DE DESHONESTIDAD ACADÉmICA}

Es muy común que se presente el plagio en obras escritas (es menos común hablar del plagio de una escultura, de una partitura o de una pintura), puesto que estas obras son más fáciles de adquirir y de reproducir en textos que se hacen pasar como propios. Por ejemplo, en las aulas, en donde tanto profesores como alumnos se dan a la tarea de citar, parafrasear, hacer alusión a un texto o un autor, a retomar ideas y frases de otras personas, en fin, pueden darse muchas formas de remitirnos al origen de donde se obtienen las ideas que se expresan.

De acuerdo con un análisis que publicó la revista electrónica Educare, es posible decir que existen tres tipos de plagio:

"Plagio total o plagio en su sentido estricto: consiste en copiar literalmente una obra y presentarla como propia.

Plagio parcial: se refiere a copiar partes de textos de una o de varias obras y colocarlos en una obra (que se presenta como propia) sin citar o dar los créditos al autor original o la fuente de donde se obtuvo. Plagio parcial por sustitución: Consiste en sustituir por sinónimos palabras contenidas en la obra original con el fin de añadirlas a una obra propia sin citar o dar los créditos al autor original o la fuente de donde se obtuvo". ${ }^{12}$

En la doctrina existen variadas investigaciones que hablan de los diferentes tipos de plagio. La variedad de plagios que pueden presentarse en la literatura se deben al análisis y a la interpretación que éstos hacen del derecho de autor. Un tipo de plagio muy cuestionable es el autoplagio; se da cuando "Un autor copia nuevamente un trabajo que ya había realizado anteriormente o usa las mismas ideas expuestas en ese trabajo pero con distintas palabras para hacerlo parecer diferente". ${ }^{13}$

Balbuena nos dice al respecto:

"Cuando un autor realiza una segunda obra, utilizando conceptos o ideas de una primera obra realizada anteriormente, esta acción no puede ser considerada plagio. La justificación de esto es que siendo

\footnotetext{
${ }^{12}$ Rojas, Martha Eugenia, "Plagio en textos académicos", Educare, vol. 16, núm. 2, mayo-agosto, 2012, pp. 55-66. [Consulta: 8 de agosto, 2015]. Disponible en: http://www.redalyc.org/pdf/1941/19412428 6004.pdf

${ }^{13}$ Imran, Naveed, Creativity and Plagiarism, Inglaterra, sIGCAs Computers and Society, 2010, p. 28.
} 
el autor el dueño de los derechos sobre su obra, se le podría perseguir equivocadamente por las modificaciones que él mismo le pueda realizar a ésta". ${ }^{14}$

Esta idea del autoplagio queda para diversas y abiertas interpretaciones, pero dado el entendido de que plagiar es apoderarse de una obra que ha sido escrita por una persona diferente de quien escribe, de quien es autor, no podría hablarse del apoderamiento de una obra escrita por el autor de ésta.

Otro tipo de plagio es "la falsa autoría". Se refiere a un tipo de plagio que se presenta cuando se incluye el nombre de una persona como el autor de un artículo, o de cualquier otro texto, sin que esa persona de la que se hace mención haya hecho contribución alguna en la realización del texto. Asimismo, se habla de falsa autoría cuando se incluye de alguna manera, por ejemplo como coautor, a la persona que está apoyando en la parte financiera del texto.

\section{El Delito de Plagio PREVisto en La LEgislación FEDERAL}

En la legislación federal vigente desde 27 de mayo de 2015, podemos encontrar el delito de plagio de manera implícita en el derecho de autor. Para ello nos remitimos al título vigésimo sexto, denominado "De los delitos en Materia de Derechos de autor", del Código Penal Federal (antes: Código Penal para el Distrito Federal en materia de fuero común, y para toda la República en materia de Fuero Federal), mismo que fue adicionado mediante decreto publicado en el Diario Oficial de la Federación el 24 de diciembre de 1996) y que consta de los siguientes artículos:

"Artículo 424. Se impondrá prisión de seis meses a seis años y de trescientos a tres mil días de multa:

I. Al que especule en cualquier forma con los libros de texto gratuitos que distribuye la Secretaria de Educación Pública;

II. Al editor, productor o grabador que a sabiendas produzca más números de ejemplares de una obra protegida por la ley federal del derecho de autor, que los autorizados por el titular de los derechos; III. A quien use en forma dolosa, con fin de lucro y sin la autorización correspondiente obras protegidas por la ley federal del derecho de autor (Reformada mediante decreto publicado en el Diario Oficial de la Federación el 17 de mayo de 1999).

\footnotetext{
${ }^{14}$ Balbuena, Pedro, "El plagio como ilícito legal", Ventana legal, 25 de mayo, 2009. [Consulta: 13 de junio, 2015]. Disponible en: http://www.ventanalegal.com/revista_ventanalegal/plagio_ilicito.htm
} 
Artículo 424 bis. Se impondrá prisión de tres a diez años y de dos mil a veinte mil días de multa:

I. A quien produzca, reproduzca, introduzca al país, almacene, transporte, distribuya, venda o arriende copias de obras, fonogramas, videogramas o libros, protegidos por la ley federal del derecho de autor, en forma dolosa, con fin de especulación comercial y sin la autorización que en los términos de la citada ley deba otorgar el titular de los derechos de autor o de los derechos conexos [...]

Artículo 424 ter. Se impondrá prisión de seis meses a seis años y de cinco mil a treinta mil días multa, a quien venda a cualquier consumidor final en vías o en lugares públicos, en forma dolosa, con fines de especulación comercial, copias de obras, fonogramas, videogramas o libros, a que se refiere la fracción I del artículo anterior [...]

Artículo 425. Se impondrá prisión de seis meses a dos años o de trescientos a tres mil días multa, al que a sabiendas y sin derecho explote con fines de lucro una interpretación o una ejecución (Artículo adicionado mediante decreto publicado en el diario oficial de la federación el 24 de diciembre de 1996).

Artículo 427. Se impondrá prisión de seis meses a seis años y de trescientos a tres mil días multa, a quien publique a sabiendas una obra sustituyendo el nombre del autor por otro nombre (Artículo adicionado mediante decreto publicado en el diario oficial de la federación el 24 de diciembre de 1996)". ${ }^{15}$

Como se puede interpretar de los artículos citados, el plagio académico (el que se presenta en aulas de los niveles desde básico hasta superior) no trascenderá y no será castigado legalmente sino existe esa obra registrada a nombre del plagiario, incluso de un tercero. Por tanto, los miles de trabajos académicos como ensayos, resúmenes, síntesis, entre otros, pueden ser calificados de plagiados, pero no sancionados jurídicamente hablando. La situación es muy diferente cuando se realizan trabajos de investigación con mayor trascendencia. Es el caso de los trabajos de investigación de tesis, ya que en ellas se manifiesta una hipótesis que se intenta demostrar a través de una investigación que se califica como propia. Es un trabajo de investigación que debe defenderse como propio, y si presenta plagios totales o parciales, será sancionado jurídicamente, si y solo si el autor original así lo discutiere; si eso no pasa, el plagiario podrá sancionarse de muchas otras formas, pero no jurídicamente hablando.

\footnotetext{
${ }^{15}$ Silva, Fernando, "Código Penal Federal comentado", 100 años Constitución, 28 de mayo, 2015. [Consulta: 29 de mayo, 2015]. Disponible en: http://info4.juridicas.unam.mx/ijure/fed/8/529.htm?s
} 


\section{UN ESTUDIO DE DERECHO COMPARADO}

En México y en el Reino Unido, en el ámbito académico, la exigencia por la especialización en un área del conocimiento es cada vez más recurrente. Día con día los espacios laborales requieren personal con niveles de estudio en los que resulta insuficiente tener una licenciatura. De modo que se convierte en una necesidad el hecho de obtener otros grados como maestría y doctorado. En todos lados se exigen niveles de preparación muy altos para ocupar puestos laborales con mejores remuneraciones; pero, al mismo tiempo que se alcanzan los niveles de especialización, se percibe una práctica muy recurrente: el plagio.

"En el Reino Unido, el 98\% de las universidades utilizan un programa llamado Turnitin [...] para analizar trabajos sospechosos, según le dijo a la BBC la compañía que lo comercializa. Este software escanea pasajes del texto y los compara con una base de datos que contiene 155 millones de informes de estudiantes, 110 millones de documentos y 14000 millones de sitios de internet". ${ }^{16}$

Lo anterior trae como consecuencia que en Reino Unido todo estudiante de nivel superior (desde que estudia una licenciatura) está siendo probado en cada uno de sus trabajos académicos, desde un ensayo hasta un trabajo de tesis. Dicha situación no es aplicable en México. ¿A qué se debe tal diferencia? La respuesta no es sencilla, pues implica una serie de situaciones éticas, profesionales y legales que son muy marcadas entre México y Reino Unido. Los reglamentos internos bajo los cuales se rigen las universidades del Reino Unido estipulan cada uno de los lineamientos que tanto alumnos como profesores deberán cumplir y hacer cumplir.

Sin embargo, en las universidades en México no existen reglamentos internos que regulen y sancionen la comisión de plagio. Parece que se sobreentiende que cuando un alumno presenta un trabajo de investigación, éste debe ser de autoría propia. Pero no sucede así en la realidad; quienes realizan investigación recurren al tan solicitado "copiar-pegar" de todo lo que encuentran en la red.

Si en un análisis sencillo hemos visto que la mejor forma de combatir el plagio en las universidades es prevenirlo, sería conveniente implementar un reglamento en las universidades que permita establecer las reglas para la

\footnotetext{
${ }^{16}$ Geoghegan, Tom, "El plagio en Reino Unido", Una voz independiente, 21 de marzo, 2015 [Consulta: 20 de noviembre, 2015]. Disponible en: http://www.bbc.com/mundo/noticias/2011/03/110302_plagio_educacion_periodismo_dp.shtml
} 
escritura de textos académicos, especialmente en la redacción de tesis (sin que esto implique que el resto de trabajos de investigación se puedan plagiar).

Por tanto, la solución radica en implementar un reglamento interno institucional en las universidades, con la finalidad de establecer las reglas bajo las cuales tendrá que desarrollarse un trabajo de investigación: especificar la forma en que deben usarse las citas, notas a pie de página, comillas, referencias del autor o de su obra; así como también dar crédito en las fuentes generales del trabajo de investigación. Resulta imprescindible estipular en el reglamento las sanciones a que será acreedor el alumno que cometa plagio, así como las faltas en las que incurriría un profesor que pase por alto la comisión del mismo. El plagio requiere preverse en un reglamento para que pueda sancionarse, ya sea con toda intención o por omisión.

\section{Herramientas online para detectarlo}

La red trae consigo oportunidades y peligros. Actualmente, con el uso de las tecnologías de la información, resulta fácil entrar a un buscador de internet y descargar información sobre cualquier tema. De la misma forma, las herramientas que nos proporciona para detectar los casos de plagio son muchas. A continuación se enlistarán las más comunes:

- Plagiarisma.Net

- Plagiarism Detect

- DOG Cop

- Turnitin

"Plagiarisma.Net: Es una herramienta que permite copiar y pegar textos o direcciones de internet, para indicar a través de colores la autenticidad del texto. Si el texto se marca en color gris significa que el texto fue "plagiado" y si aparece en amarillo, quiere decir que el texto es original. ${ }^{17}$ Plagiarism Detect: Plagiarism detect es una herramienta para detectar si hay plagio en un texto, y en qué porcentaje se da éste. Incluye además las páginas web de las que se ha copiado la información, diferenciando entre las que guardan mayor similitud". ${ }^{18}$

"DOC Cop: Es una herramienta de detección de plagio. Cop DOC crea informes que muestran la correlación entre documentos o un documento y la web. DOG Cop no toma los derechos de autor o

\footnotetext{
${ }^{17}$ Sepúlveda, Martha, "Plagiarisma.Net", Aprendizaje digital, 27 de agosto, 2012. [Consulta: 11 de julio, 2015]. Disponible en: https://descubrirconectarguiar.wordpress.com/2012/08/27/plagiarisma-net/

${ }^{18}$ Bautista, Marila, "Plagiarism Detect", Crea TICinnova, 14 de julio, 2013. [Consulta: 11 de julio, 2015]. Disponible en: http://creatic.innova.unia.es/otros/deteccion-de-plagio/plagiarism-detect-detail
} 
propiedad intelectual del material. DOC Cop reúne las pruebas y proporciona la información necesaria para determinar si se ha producido plagio". ${ }^{19}$

"Turnitin: Se trata de una herramienta muy completa dirigida a profesores, alumnos e investigadores creada por cuatro estudiantes de la Universidad de California en Berkeley y disponible en seis idiomas (inglés, español, alemán, francés, portugués y turco). A través de copiar/pegar un fragmento de texto, evalúa si existen coincidencias en la red". ${ }^{20}$

Turnitin, al igual que los muchos otros softwares que existen para detectar plagio, compara el trabajo sometido a análisis con la base de datos que contienen esos softwares. Pero eso no nos asegura que el trabajo presentado por un alumno sea plagiado o no; eso nos explica simplemente que el texto del alumno ya se encuentra en otro escrito. Es hasta contradictorio pensar que lo que escribe un estudiante no debe existir en otro texto, pues las investigaciones, entre más citas de autores tengan, más ricas son en aporte al conocimiento, y tienen así el sustento bibliográfico, hemerográfico o electrónico de donde se obtuvo la información presentada.

\section{PRÁCTICAS DE DESHONESTIDAD ACADÉmICA}

Jorge Joel Reyes Méndez, biólogo, doctor en educación y profesor de la Universidad Autónoma Metropolitana, aplicó un cuestionario a 180 estudiantes voluntarios de esa universidad, con la finalidad de conocer cuál es la práctica de deshonestidad académica más común que cometen. Los resultados se presentan en el siguiente cuadro.

\footnotetext{
${ }^{19}$ Rodríguez, Mario, "DOC Cop", DOCCOP, 31 de marzo, 2015. [Consulta: 11 de julio, 2015]. Disponible en: https://www.doccop.com/index.html

${ }^{20}$ Ávila, José "Turnitin", Somamfyc, 15 de junio, 2015. [Consulta: 11 de julio, 2015]. Disponible en: https://nuevastecsomamfyc.wordpress.com/2015/06/15/herramientas-plagio-i/
} 
Cuadro 1 "Prácticas de deshonestidad académica más comunes en la Universidad Autónoma Metropolitana"

\begin{tabular}{|l|c|}
\hline Prácticas de deshonestidad académica & $\begin{array}{l}\text { Porcentaje de } \\
\text { estudiantes que han } \\
\text { incurrido }(\%)\end{array}$ \\
\hline Entregar un trabajo previamente presentado por él mismo & 29.6 \\
\hline Entregar un trabajo realizado previamente por otro estudiante & 31.8 \\
\hline Elaborar un documento para otra persona & 34.2 \\
\hline Copiar texto de fuentes impresas y no citarlo & 83.8 \\
\hline Copiar texto de páginas web y no citarlo & 89.2 \\
\hline Bajar un trabajo completo de internet y entregarlo como propio & 34.3 \\
\hline
\end{tabular}

Fuente: Elaboración propia, con base en: Nava, Amapola, "Científicos podrán utilizar software para detectar plagio", Entre pares, 14 de septiembre, 2016. [Consulta: 19 de diciembre, 2016]. Disponible en: http://www.conacytprensa.mx/index.php/tecnologia/tic/10330-cientificos -podran-utilizar-software-para-detectar-plagioCUADRO

Derivado de la interpretación de los resultados, podemos ver que las seis prácticas de deshonestidad académica se resumen en una que se llama "plagio". Si retomamos este estudio, podremos darnos a la tarea de prevenir que se dé esta práctica o en su caso corregirla. Por lo tanto, la implementación de un reglamento interno en las universidades que sancione la práctica del plagio resultaría una solución.

\section{9. ¿CÓMO FRENAR SU USO EN LAS TESIS?}

Explica Juan Manuel Magaña Rufino que uno de los tipos penales autorales se comete cuando:

"Alguien publique, con conocimiento una obra substituyendo el nombre del autor por otro nombre. Este delito normalmente se conoce como plagio y se persigue por querella de parte ofendida. Cabe señalar que en la legislación mexicana los términos plagio y secuestro se emplean como sinónimos por lo cual hay que hacer la especificación cuando se hable de plagio literario". ${ }^{21}$

Ante la ausencia de sanciones precisas respecto de la figura del plagio, en tanto que es una infracción a los derechos de autor, lo más conveniente sería

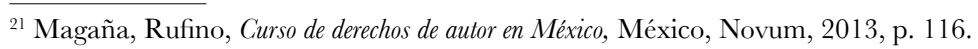


la implementación de un reglamento interno en las instituciones educativas, con la finalidad de establecer los lineamientos bajo los cuales, tanto estudiantes como catedráticos, directores de tesis, asesores de contenido y de metodología de tesis y jurado encargado de evaluar al alumno, deberán conducirse en el desarrollo y presentación de los proyectos de investigación.

Derivado del tipo penal de plagio al que hace referencia Magaña Rufino, podemos observar que en la legislación mexicana resulta confuso, pues se debe ser muy claro y llamarlo plagio literario para saber que estamos hablando del contexto del derecho de autor. Sin embargo, es preciso señalar que la acción de hacer pasar una obra a nombre de otro es encuadrar esa conducta al tipo penal de "plagio", el cual, hasta este momento, es un delito que se persigue por querella de parte ofendida. Otra etapa es la relativa a la reparación del daño derivada del encuadramiento del tipo penal de plagio. Explica José Manuel Magaña Rufino que:

"La violación a las disposiciones establecidas en la Ley Federal del Derecho de Autor y en las sanciones administrativas y penales conlleva a la reparación del daño material o moral causado, si el afectado lo solicita. A tales efectos, la propia Ley Federal del Derecho de Autor señala que esta reparación en ningún caso será inferior al 40\% del precio de venta al público del producto o servicio con el que se cometió el delito". ${ }^{22}$

Entramos a este apartado hablando del tipo penal de plagio y de la reparación del daño porque es importante resaltar dos puntos antes de empezar a difundir una cultura que prevenga y sancione la comisión del plagio académico. De los dos párrafos anteriores rescatamos que: la definición de plagio es ambigua, y para que dicha práctica sea sancionada debe solicitarlo quien se ve afectado. Es decir, si el autor de una obra no se entera de que otra persona plagió su obra, nunca va a acusar que se ha cometido plagio en su contra. Por ejemplo, en un caso hipotético, un alumno de licenciatura en Derecho toma un libro del doctor Víctor Castrillón y Luna para hacer su tesis, y copia y pega un sinfín de párrafos sin darle el crédito. Pongamos ahora otro caso hipotético: una persona copia y pega párrafos y capítulos enteros de un libro del doctor Víctor Castrillón y Luna para armar un libro que lleva su nombre, y omite dar el crédito al autor; imprime ese libro y lo distribuye para venta.

En ambos casos, se plagia la obra de Víctor Castrillón, solo que, en el primer ejemplo, la obra no se registra, pues no es requisito de la Universidad y el alumno no obtiene un lucro, pues su tesis no la vende. En el caso dos, en cambio, sí hay registro y también hay lucro. Lo cierto es que en ambos casos

${ }^{22}$ Ibidem, p. 117. 
Víctor Castrillón es quien puede decir que se ha cometido plagio en su contra, y es él quien puede iniciar un juicio y pedir la reparación del daño, según sea el caso. Vemos de esta forma que de acuerdo a lo estipulado por la Ley, si el doctor Víctor Castrillón se percatara de que en ambos casos plagiaron su obra, sólo podría proceder en contra del segundo, pues registró su obra y obtuvo un lucro. ¿Cómo procedemos entonces a sancionar al alumno que plagió la obra del doctor Víctor Castrillón?

Con el ejemplo anterior, aterrizamos en el campo del plagio académico, ese que se comete en la elaboración de tesis, y en donde bajo lo estrictamente estipulado por la Ley Federal del Derecho de Autor, vemos que parece que la comisión de plagio en este contexto académico no está regulada, pues quien en algún momento determina si una tesis es plagiada o no es el jurado que la evalúa.

Por lo anteriormente expuesto, consideramos que para prevenir y sancionar la práctica del plagio en el contexto académico esa figura debe estar estipulada en un reglamento. Para poder hacer alusión a los alcances reales que jurídicamente tiene un reglamento, es preciso referir el concepto de éste en ámbitos estrictamente jurídicos.

"Reglamento: Norma jurídica de rango inferior a la ley dictada por órgano que tiene atribuida potestad reglamentaria. Los reglamentos no pueden regular materias reservadas a la ley ni infringir normas con dicho rango. Para que produzcan efectos jurídicos deben ser publicados en el diario oficial que corresponda y tienen vigencia indefinida hasta que se modifiquen por otras normas de mayor o igual rango. Según su relación con la ley, la doctrina alemana los clasifica en: 1) reglamentos ejecutivos o secundum legem, que ejecutan y aplican la ley; 2) intra legem, que completan una ley añadiendo supuestos o preceptos nuevos, y 3) reglamentos o praepter legem, que regulan ex novo una determinada materia, sin existencia concreta de una ley, siempre que en aquella materia no exista reserva de ley". ${ }^{23}$

Haciendo un análisis meticuloso de las líneas anteriores, podemos situarnos en el supuesto número dos: intra legem. Es decir, aquellos reglamentos que completan una ley "añadiendo" supuestos o preceptos nuevos. Es notorio, según lo dispuesto en la presente investigación, que la Ley Federal de Derechos de Autor no contempla los supuestos de plagio, y en consecuencia tampoco prevé sanciones en caso de que dicho suceso se presente. En razón de lo anterior, resultaría viable que instituciones de educación autónomas puedan establecer

\footnotetext{
${ }^{23}$ Fernández, Jorge, "Reglamento", Diccionario jurídico, 12 de julio, 2003. [Consulta: 26 de julio, 2015]. Disponible en: http://www.enciclopediajuridica.biz14.com/d/reglamento/reglamento.htm
} 
de manera interna un reglamento que estipule cada una de las condiciones que deberá cumplir el trabajo de investigación de una tesis para obtener el grado de estudios correspondiente.

Por lo tanto, si las instituciones autónomas de educación superior implementaran un reglamento interno con la finalidad de establecer los supuestos en los que se comete plagio, y al mismo tiempo estipula las sanciones que deberán aplicarse al sujeto que cometa el plagio, se lograría prevenir y sancionar la práctica de plagio en las investigaciones realizadas.

Podemos proponer que en ese reglamento se empiece por definir qué se va a entender por plagio, así como establecer sanciones para toda aquella persona que se vea involucrada en su comisión.

A continuación, presentamos una propuesta de definición de plagio y de sanciones para la comisión del mismo, que podrían emplearse en la redacción de un reglamento.

Definición de plagio: cometerá plagio el alumno que a sabiendas de que un texto no es de su autoría, lo presente como tal u omita dar el crédito al autor.

El plagio señalado a un alumno por un jurado deberá estar debidamente fundamentado y sustentado con pruebas fehacientes.

Para el caso específico de tesis que no tienen como requisito el voto aprobatorio del jurado, este último podrá señalar comisión de plagio en el momento en que se sustenta el examen, pues es hasta entonces cuando puede emitir su veredicto.

Para el caso específico de tesis que tienen como requisito el voto aprobatorio del jurado, este último podrá señalar comisión de plagio en el momento de la emisión de su voto, siendo este negativo, de modo que no podrá asignarse fecha de examen hasta que subsane la comisión de plagio.

Sanciones: para el caso de que en un examen profesional o de grado, un alumno cometa plagio, se suspenderá su examen y se le reasignará una fecha para volver a presentarlo. Si en esta segunda oportunidad de presentar su examen incurre en plagio, se le dará de baja de la licenciatura o posgrado que corresponda.

En esta segunda presentación de tesis, el alumno, junto con su mismo asesor de tesis, tendrá que elaborar una segunda investigación para presentarla ante jurado en un plazo no menor a seis meses ni mayor a ocho.

Asimismo, en esta segunda presentación de tesis, el alumno no podrá ser acreedor a ningún tipo de mención honorífica.

$\mathrm{Al}$ profesor, tutor o director de tesis que haya aprobado la tesis para su defensa ante jurado, aun cuando esta contenga plagio, no podrá dirigir tesis en los seis meses posteriores al señalamiento de dicha falta. Asimismo, tendrá que subsanar el primer trabajo plagiado junto con su alumno, para poder presentarlo en una segunda y última oportunidad para obtener el título o grado de que se trate. 


\section{CONCLUSIONES}

Después de haber analizado la figura del plagio en el contexto del derecho de autor, y hacer hincapié en el tema de la práctica desmedida del plagio en México, nos permitimos manifestar que, en México, en las aulas de las universidades que forman licenciados, maestros y doctores, a diario se observa el plagio como una acción común, y no se castiga porque a través de un mundo de simulación, hacemos como que escribimos, hacemos como que leemos, y así se obtienen los grados.

Por lo anterior, consideramos viable proponer como medida preventiva y correctiva la creación y aplicación de un reglamento interno en las universidades, donde se lleven a cabo defensas de tesis ante jurado. De este modo, tanto los miembros del jurado que evalúen al sustentante de tesis como el tesista, estarán sujetos a lo dispuesto en el reglamento. Dicho reglamento deberá establecer desde las condiciones básicas que definan qué se entenderá como plagio, así como también las sanciones que le serán aplicadas a quien lo cometa.

De este modo, el objetivo de la presente investigación se logra debido a que el hecho de fomentar una cultura por el respeto del derecho de autor en el contexto universitario implica dar a conocer los elementos básicos del mismo, tal y como se explica en este artículo. Si desde que un investigador se está formando aprendiera a respetar el derecho moral que le es intrínseco al autor de otra obra, se evitaría la comisión de plagio. Pero dado que tal cultura por el derecho de autor no existe, entonces se deben tomar medidas correctivas frente a su comisión. 